EGU2020-8574

EGU General Assembly 2020

(c) Author(s) 2020. This work is distributed under

the Creative Commons Attribution 4.0 License.

\title{
Environmental and climate dynamics in northeastern Siberia according to diatom oxygen isotopes
}

\author{
Svetlana Kostrova ${ }^{1,2}$, Hanno Meyer ${ }^{1}$, Luidmila Pestryakova ${ }^{3}$, Boris Biskaborn ${ }^{1}$, Francisco \\ Fernandoy ${ }^{4}$, and Marlene Baumer ${ }^{5}$ \\ ${ }^{1}$ Alfred Wegener Institute Helmholtz Centre for Polar and Marine Research, Research Unit Potsdam, Potsdam, Germany \\ (svetlana.kostrova@awi.de; hanno.meyer@awi.de; boris.biskaborn@awi.de) \\ ${ }^{2}$ Vinogradov Institute of Geochemistry, Siberian Branch of Russian Academy of Sciences, Irkutsk, Russia \\ (kostrova@igc.irk.ru) \\ ${ }^{3}$ North-Eastern Federal University of Yakutsk, Institute of Natural Sciences, Yakutsk, Russia (lapest@mail.ru) \\ ${ }^{4}$ Facultad de Ingeniería, Laboratorio de análisis isotópico, Universidad Andrés Bello, Viña del Mar, Chile \\ (francisco.fernandoy@unab.cl) \\ ${ }^{5}$ Institute of Geology and Mineralogy, University of Cologne, Cologne, Germany (mbaumer@uni-koeln.de)
}

The sedimentary sequence from Lake Emanda $\left(65^{\circ} 17^{\prime} \mathrm{N} ; 135^{\circ} 45^{\prime} \mathrm{E} ; 675 \mathrm{~m}\right.$ a.s.l), one large freshwater body $\left(33.1 \mathrm{~km}^{2}\right)$ in the continuous permafrost of the Verkhoyansk Mountains, has been investigated within the German-Russian 'Paleolimnological Transect' (PLOT) project. It provided important insight into the environmental and climate dynamics in northeastern Siberia.

Well preserved diatoms occur only in the upper 125 -cm interval of a 6.1-m sediment core (Co1412) covering the last ca. 13.4 cal. ka BP, and are mostly dominated by Cyclotella iris (up to 84\%). The diatom succession is enriched by fragilarioid assemblages in the interval from ca. 11.0 to 13.0 cal. ka BP, while Aulacoseira am bigua is more frequent between 8.5 and $6.5 \mathrm{cal}$. ka BP. Diatoms were purified to $>98 \% \mathrm{SiO}_{2}$ and $<0.8 \% \mathrm{Al}_{2} \mathrm{O}_{3}$ suitable for oxygen isotope $\left(\delta^{18} \mathrm{O}_{\text {diatom }}\right)$ analysis. The $\delta^{18} \mathrm{O}_{\text {diatom }}$ values were corrected for contamination and range between $+22.5 \%$ and $+27.3 \%$. Maximum $\delta^{18} \mathrm{O}_{\text {diatom }}$ values $(+26.7$ to $+27.3 \%$ ) are registered between 9.0 and $9.9 \mathrm{cal}$. ka BP and probably reflect a thermal maximum and/or very dry conditions in Early Holocene. The absolute minimum $(+22.5 \%)$ in the $\delta^{18} \mathrm{O}_{\text {diatom }}$ record is marked at 0.4 cal. ka BP and likely corresponds to the Little Ice Age. In general, a gradual depletion of $4.8 \%$ in $\delta^{18} \mathrm{O}_{\text {diatom }}$ is observed within the last 10 cal. ka, in line with an overall Holocene temperature decrease.

Our conclusions are based on a comprehensive investigation of both the modern hydrological system and diatom species analyses. The most recent $\delta^{18} \mathrm{O}_{\text {diatom }}=+24.2 \%$ combined with the present day lake water isotope composition (mean $\delta^{18} \mathrm{O}_{\text {lake }}=-16.5 \%$ ), indicates a reasonable water-silica isotope fractionation $(\alpha=1.0414)$ yielding a water temperature of $12{ }^{\circ} \mathrm{C}$. The data demonstrate that the $\delta^{18} \mathrm{O}_{\text {diatom }}$ variability is associated with changes in the lake water isotopic composition rather than with lake temperature. The present water isotopic composition of Lake Emanda displays substantial evaporation effects, likely further influenced by air temperature and atmospheric circulation. 
